\title{
Research the Impacts of Covid-19 on U.S. Entertainment and Publishing Industry Based on Fama-French Five Factor Model
}

\author{
Boyang Wang ${ }^{1, *}$ \\ ${ }^{1}$ Department of Economics, University of Birmingham, Birmingham B15 2TT, United Kingdom \\ *Corresponding author. Email: bxw803@student.bham.ac.uk
}

\begin{abstract}
The outbreak of COVID-19 in early 2020 has had a huge impact on the global economy. This paper aims to analyze the impact of the outbreak on the entertainment industry and publishing industry. Stock market data of selected industries is used for analysis, and Fama-French five-factor model is adopted to evaluate the influence of Covid-19. The data for each industry is divided into pre-epidemic and post-epidemic groups. Then the validity of each factor in the industry will be tested by multiple linear regression, and the correlation coefficients will be obtained. The results indicate that the market portfolio factor (MKT) and size factor (SMB) in the model have good significance in the stock market of the two industries. In addition, their coefficients all went up after the outbreak, suggesting that they were less negatively affected by the pandemic than the overall market. It is worth noting that both industries' book-tomarket ratio (HML) was insignificant before the pandemic and became significant during the pandemic. That may be due to investor pessimism, which has led to a clear style division between value and growth stocks. However, the significant changes of profitability factor (RMW) and investment factor (CMA) in the two industries are very different. This paper speculates the reasons for the changes of the two factors in the two industries. The study has laid a foundation for economic analysis and prediction of such events that will greatly impact the economy in the future. At the same time, the speculation also provides inferential ideas for subsequent studies in these two industries.
\end{abstract}

Keywords: Fama-French Model, Covid-19, Entertainment, Publishing, U.S. stock market.

\section{INTRODUCTION}

The global outbreak of COVID-19 in February 2020 has had a huge impact on the world economy. During its rampancy, most brick-and-mortar businesses were forced to shut down. Because these enterprises cannot make profits, it is difficult to pay the employees on time and in quantity. The wage earners' consumption desire is also reduced because of unemployment and the lack of income security.

In the consumer sector, where bricks-and-mortar retailers have generally suffered, companies with online sales platforms have seen new opportunities. Traditional consumer industries are shifting to online shopping because going out to shop can carry more health risks than online shopping. This shift is now evident in entertainment consumption because it is easier for consumers to directly access cultural and entertainment products and services online than other types, bringing great changes and new opportunities to the entertainment industry.

Based on the mean-variance analysis method proposed by American economist Markowitz in 1952, Sharp first proposed the capital asset pricing model in 1964. This model is widely used in empirical analysis, so that rich financial, statistical data can be used systematically and effectively. It is an important basis for the actual research and decision-making of securities investment. It is the basis of modern financial market price theory, which is widely used in the field of investment decisions and corporate finance. Subsequently, economists proposed a variety of optimization models to optimize the accuracy of the CAPM model in describing the market. Fama and French successively introduced size premium and bookto-market factors into their three-factor model and profitability and expected investment factors into their five-factor model (FF5F). The accuracy of the FF5F 
model is extremely important to investors who use FF5F to estimate the future average return of a portfolio of stocks when making investment decisions. However, the huge impact of the epidemic on the economy has brought many uncertain factors to the market, so it is necessary to study whether the 5-factor model is still accurate in predicting the future average returns of stocks.

It is important to study the impact of COVID-19 on the global economy. Lee studied how sentiment about the coronavirus affected sector returns in the stock market. He believes that online information, available in the public domain, can greatly influence investors' decisions. Especially in a market crisis like COVID-19, any news can significantly affect investor sentiment and, therefore, investment decisions. He used DNSI's coronavirus searches and Big data from Google Trends as indicators of attention to the epidemic and then compared them with stock market data from 11 specific industries. His empirical results show that the sectors most affected by COVID-19 are communications services, discretionary consumption, industry, energy and materials [1]. Narayan and Phan focused on the impact of specific events related to COVID-19 on the stock market in the same period. They conducted a descriptive analysis of how COVID-19 affected the financial system. They see the market as overreacting to the coronavirus, as it does to unexpected news. They summarize what governments have done to respond to the pandemic and understand the differences in the results of different government measures. Ultimately, they summed up the data and found that the single most disruptive event for stocks was the coronavirus announcement. At the same time, the combination of travel bans, lockdowns and stimulus packages also had a real negative impact [2].

However, even in the midst of the COVID-19 pandemic, investment opportunities still exist, and formulating appropriate investment directions and strategies is an important goal for us. Tashanova et al. combined practical examples and data analysis to identify investment opportunities during the COVID-19 pandemic. They argued that most businesses in the market had suffered huge economic losses. The government has ordered businesses to close and people to stay at home to stop the spread of the disease, with the most vulnerable being indebted small companies that have just entered the market. However, they believe it can also be a good time to profit by analyzing the market. Some industries, such as online entertainment, online education, food and healthcare, are seeing new opportunities due to COVID-19, they said. [3] The differences in the performance of stocks in the pandemic have also been studied: He et al. empirically discussed the impact of COVID-19 on stock prices of various industries in China in 2019 and summarized the characteristics of industries with high and low impacts.
By grouping companies with different equity properties, they found that the share prices mainly fell in China's traditional industries, and the cumulative returns of state-owned enterprises at each node of the outbreak were significantly negative. In contrast, non-stateowned enterprises have a small growth, but the hightech industry has ushered in a development opportunity. They cite the construction of $5 \mathrm{G}$ networks as an example of how the COVID-19 pandemic has boosted consumption in online education, smart homes, immersive games and other areas, pushing China's industrial chain to upgrade [4].

Fama French five factor model is a good theory to analyze stock price trends. Fama and French proposed their five-factor model that was a step up from their previous three-factor model in 2015 . They claimed that the factors forecasting the profitability and investment of stock companies might better demonstrate the relationship between stocks' characteristics and average returns than the HML in the three-factor model did. However, there is a problem that the 5-factor model has insufficient explanatory power for the average earnings of very small companies [5]. In 2015, Cakici used the capital market data of 23 developed countries to test the explanatory power of the five-factor model. By comparing the results of the three, four, and five factor tests, he found that the profitability and investment factors significantly increased the explanatory power of the pricing models in the North American and European stock markets. However, these new factors did not make the model much more efficient in Japan and the AsiaPacific region. In addition, he found that the model was better at predicting regional data than global data and speculated that the five-factor model was more effective for the American market than for international markets [6].

More specifically, Hou used the data of retail industry performance from September 2019 to August 2020 for regression and then used the Fama French fivefactor model to calculate the coefficients of five factors. He concluded that the retail sector's performance was similar to that of the US market as a whole since the market's total portfolio return (MKT) coefficient was close to one; After the outbreak of the epidemic, the effectiveness of RMW and CMA factors weakened, indicating that a company's profitability and investment style had little impact on the return rate of investment in the retail industry, while HML became a significant factor. Investing in a company with a high book-tomarket ratio would be more profitable. Ultimately, he advises investors to focus on small, high-book-tomarket companies and retailers actively engaged in ecommerce and adopting advanced technologies [7]. Nguyen et al. had a similar idea. In 2020, they studied the impact of COVID-19 on consumers' willingness to buy books online and classified this impact as a situational impact. They also proposed that dividing 
consumer motivation into utility motivation and hedonic motivation could play a certain role in predicting consumers' willingness to buy books online. Moreover, they also focused on Vietnam, a key emerging economy in Southeast Asia, and studied online shopping and book-buying behavior in emerging market economies. Their findings suggest that the impact of COVID-19 on consumers' willingness to buy books online mainly includes the closure of brick-and-mortar retail outlets, the health risks associated with visiting brick-andmortar bookstores, and the increased marketing intensity of online bookstores during the epidemic, all of which have accelerated the shift from traditional book consumption to online book purchases [8]. Besides, Guren et al. studied the impact of COVID-19 on the book publishing, retail and related industries. In general, they argued, book retailers were hit harder than publishers. A significant difference, they said, is the shift from traditional book consumption to online consumption, where sales have exploded. This extends to education, where higher education publishers who previously invested in digital learning initiatives acquired positive returns, and the trend of distance learning and digitization accelerated. At the same time, government budgets for libraries were cut. They argued that companies benefit by providing products or services that consumers can use directly at home [9]. Moreover, $\mathrm{Li}$ et al. compared the performance of the three-factor model and the five-factor model for the GAME industry in the US market before and after the outbreak of COVID-19 and discussed the possible reasons for these performances. Their results showed that both multifactorial models performed better in the U.S. stock market after the pandemic than they did before. Compared with the three-factor model, the non-factor model is more effective. They identified factors that were consistently significant in both models and became more explanatory after the outbreak as MKT (association with market risk) and SMB (size of firm) [10].

This paper will focus on the impact of COVID-19 on the Entertainment industry and the Printing and Publishing industry, two industries that both have the trend of transition from offline consumption to online, on the stock prices. After that, the linear regression method will be used to examine whether the factors in FF5F can still effectively predict the average return of stocks in both industries during the epidemic period and compare the effectiveness with that before the epidemic. Finally, this paper will study the actual changes caused by the epidemic in these two industries and use them to explain the regression results obtained by the FF5F model.

\section{METHOD}

The model tested in this paper is the Fama French five-factor model (FF5F). Fama and French proposed it in 2015 as an upgrade to the FF3F they built in 1993, directing at forecasting the average return of stocks by considering the size, value, profitability, and investment patterns.

$\mathrm{E}\left(R_{i}\right)-R_{f}=\alpha+\beta_{\mathrm{MKT}} *\left[E\left(R_{m}\right)-R_{f}\right]+\beta_{\mathrm{SMB}} * S M B+$ $\beta_{\mathrm{HML}} * H M L+\beta_{\mathrm{RMW}} * R M W+\beta_{\mathrm{CMA}} * C M A+\varepsilon_{\mathrm{i}}$ (1)

In this equation, $E\left(R_{i}\right)$ represents the expected average long-term return of an asset or a portfolio, $R_{f}$ represents the risk-free rate of return in the market, and $E\left(R_{m}\right)$ is the long-run expected average return of the market. SMB (Small Minus Big), HML (High Minus Low) and RMW (Robust Minus Weak) are the differences between assets or investment portfolio and market portfolio in specific aspects -SMB is a measure of the size of a company, HML is the valuation level of a company, RMW is the forecast of a company's profitability, and CMA is the expectation of the amount of investment received by the company. The $\beta$ values represent the exposures of these factors in the form of coefficients in the equation. $\alpha$ is the unexplained part of these factors, and if the deviation between asset and market portfolios is fully captured by the five $\beta$ values in the model, then $\alpha$ will be equal to zero.

\section{RESULTS}

This paper adopted data in fun and books industries from the research returns data of 49-industry portfolios worked by Kenneth R. French, using daily data from May 1, 2019, to February 28, 2020, to study the effectiveness of the pre-pandemic FF5F, while daily data from March 1, 2020, to November 31, 2020, were used to study the effectiveness of the model during the pandemic. This paper used a $95 \%$ confidence interval to perform multiple linear regression on the selected data to facilitate data comparison. Results of the fun industry are shown in Table I and Table II, while the results of the books industry are shown in Table III and Table IV.

Table 1. FF5F Regression in Fun Industry Before COVID-19 (2019.05.01-2020.02.28)

\begin{tabular}{cccc}
\hline & Coefficients & t-value & P-value \\
\hline Mkt-RF & 0.789 & 13.101 & 0.000 \\
SMB & 0.537 & 4.739 & 0.000 \\
HML & -0.114 & -0.978 & 0.329 \\
RMW & 0.521 & 2.749 & 0.007 \\
CMA & -0.452 & -2.016 & 0.045 \\
\hline
\end{tabular}

Table 2. FF5F Regression in Fun Industry During COVID-19 (2020.03.01-2020.11.31)

\begin{tabular}{cccc}
\hline & Coefficients & t-value & P-value \\
\hline Mkt-RF & 1.025 & 17.145 & 0.000 \\
SMB & 0.982 & 6.380 & 0.000
\end{tabular}




\begin{tabular}{lccc} 
HML & 0.695 & 5.487 & 0.000 \\
RMW & 0.491 & 1.911 & 0.057 \\
CMA & -2.268 & -6.898 & 0.000 \\
\hline
\end{tabular}

Table 3. FF5F Regression in Books Industry Before COVID-19 (2019.05.01-2020.02.28)

\begin{tabular}{cccc}
\hline & Coefficients & t-value & P-value \\
\hline Mkt-RF & 0.738 & 5.622 & 0.000 \\
SMB & 0.995 & 4.028 & 0.000 \\
HML & -0.014 & -0.055 & 0.956 \\
RMW & 0.266 & 0.645 & 0.520 \\
CMA & 0.363 & 0.743 & 0.458 \\
\hline
\end{tabular}

Table 4. FF5F Regression in Books Industry During COVID-19 (2020.03.01-2020.11.31)

\begin{tabular}{cccc}
\hline & Coefficients & t-value & P-value \\
\hline Mkt-RF & 0.804 & 19.684 & 0.000 \\
SMB & 0.606 & 7.881 & 0.000 \\
HML & 0.028 & 0.349 & 0.727 \\
RMW & 0.361 & 2.808 & 0.005 \\
CMA & -0.452 & -2.016 & 0.045 \\
\hline
\end{tabular}

From Table I to Table IV, we can conclude that

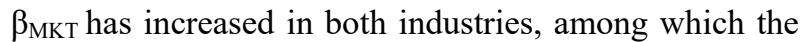
increase rate of the entertainment industry is slightly higher than that of the book industry. This suggests that companies in these two sectors have become more profitable by taking systemic risks after the outbreak, reflecting their outperformance against the market. SMB factors in the two industries were also significant before and during the epidemic. The trend was similar to that of the MKT factor: $\beta_{\mathrm{SMB}}$ in the entertainment industry showed a significant increase. In contrast, $\beta_{\mathrm{SMB}}$ in the book industry showed a relatively small increase. This shows that the logic that small and medium-sized companies make more money in the pandemic still holds true in the industries discussed in this article and even more so in the entertainment industry. The HML factor became significant during the pandemic. It showed a positive correlation in both industries, suggesting that companies with higher book-to-market $(\mathrm{B} / \mathrm{M})$ ratios became relatively more profitable during the pandemic than those with lower B/M ratios. From the regression results, RMW and CMA acted more like redundancy factors in this epidemic, showing different effects in the two industries. In the entertainment industry, the RMW factor was significantly and positively correlated before COVID-19. Still, it became insignificant after COVID-19, while the performance of RMW in the publishing industry was completely opposite to that in the entertainment industry. In CMA, the two industries also show completely opposite significance: in the entertainment industry, both periods are significant and negatively correlated, while in CMA, it is not significant all the time.

\section{DISCUSSION}

This paper compared the entertainment industry and publishing industry with the data before and after the COVID-19 outbreak was announced in the United States, verified the effectiveness of the Fama French five-factor model in the epidemic, and analyzed the impact of the epidemic on the stocks of companies in these two industries in the American market.

\section{$4.1 \mathrm{Mkt}$}

The $\beta_{\text {MKT }}$ of the entertainment industry increased a lot from 0.79 to 1.02 , while the coefficient of the printing and publishing industry changed relatively little, from 0.74 to 0.78 . There may be three reasons why the market portfolio increased more risk-taking in the COVID-19 outbreak than in the industries concerned. First, the industries hardest hit by the epidemic greatly affected the market portfolio. Second, the profits of the industries selected in this paper are not affected by COVID-19. Third, selected industries may have found new market opportunities amid the COVID-19 pandemic.

The first possibility is supported by the view put forward by He et al. (2020) [4]. They pointed out that the traditional industries in which state-owned enterprises with large market value are located generally suffer more losses than those in which non-state-owned small enterprises are abundant. Postal, transportation, environment, energy and other industries with large market values have suffered heavy losses due to their difficulties in normal business development, long project cycle and large capital investment.

For the entertainment industry, the business development of most companies has also been greatly affected, but games and live broadcasting are two exceptions. First, their business is entirely online, so segregation has not cut into their revenues. On the contrary, individuals thus have a lot of free time in their own homes. When you can't go outside, playing games and watching live videos are naturally the best forms of entertainment.

Based on data research, Guren et al. (2021) [9] concluded that the book publishing industry suffered much less impact than book retailers in the COVID-19 pandemic. This is because the publishing industry's supply chain problems were serious at the beginning of 2020, but they were resolved by the companies themselves in the second half of the year. At the same time, book sales are strong -- sales in each month of 2020 are almost uniformly ahead of the same period in 2019 , and books in several subjects increased by more than 20 per cent year-on-year at the end of 2020 . Hence, no major companies in the publishing industry went bankrupt during the pandemic. 


\section{$4.2 S M B$}

The coefficient of the entertainment industry increased significantly, from 0.53 to 0.98 , while that of the book industry was relatively stable, 1.00 and 1.03 respectively before and during the epidemic. This means that the average return on investing in small-company stocks in both sectors was higher than the average return on investing in large-company stocks, and the pandemic has made the difference even greater.

There are two good reasons for the sharp rise in $\beta_{\mathrm{SMB}}$ in the entertainment industry: First, the big players in the industry have been hit harder. Second, innovation has allowed small companies in the industry to grow rapidly. In the American entertainment industry, large volume companies are mainly film and television companies or sports-related companies. The big six Hollywood studios and the NBA are well-known examples. Because of the quarantine policy, movie theaters across the United States have closed, cinemas have lost their source of income, and film production and release have been delayed. All this has brought a heavy blow to the Film industry in the United States. The same applies to sports event promoters, amusement parks and talent agencies. There is no doubt that big Volume in the US entertainment industry has suffered a huge loss. However, while major entertainment companies have been hit hard by the ban, new industries such as gaming and livestreaming have emerged in 2020 at a furious pace. Looking at super Data, Li et al. [10] found that US consumers purchased $\$ 10.5$ billion worth of games in April 2020 due to quarantine policies. The game industry, which is already growing rapidly, has seen a surge in share prices in 2020 as online consumption and services provide investors with easy and accurate forecasts. This trend is also reflected in the live streaming industry, which is also common among small and medium-sized enterprises and the fledgling esport industry.

\section{$4.3 \mathrm{HML}$}

HML in both the book industry and the entertainment industry has gone from being insignificant before the pandemic to be significant during the pandemic. During the pandemic, the $\beta_{\mathrm{HML}}$ of the entertainment industry was 0.695 , and the $\beta_{\mathrm{HML}}$ of the publishing industry was 0.028 . It can be seen that the relationship between the book-to-market ratio and earnings in the entertainment industry is significantly stronger than that in the publishing industry. The $\mathrm{B} / \mathrm{M}$ ratio may have become effective after the pandemic because of a change in investor sentiment. It reflects the degree of investors to the company's recognition, when a huge negative news, the index may well reflect the differentiation on the style of the investment: the value investors than the high book value of growth stocks are relatively stable operation, and speculators growth stock of concern may because of the huge negative news show a downward trend.

\section{$4.4 R M W \& C M A$}

The effectiveness of RMW and CMA did not show a uniform trend in the regression results of the two industries, making it difficult to prove that these changes are related to the epidemic. Therefore, this paper puts forward some conjectures, which need to be confirmed by subsequent studies.

$\beta_{\text {RMW }}$ of the entertainment industry was significantly and positively correlated with 0.52 before the epidemic but became insignificant after the epidemic. This may be because the epidemic, as an uncertain factor, causes a large deviation between the actual profit and the expected profit, and the operating cash flow of cinemas, amusement parks and other public entertainment places in the entertainment industry is greatly affected, which leads to the inaccurate prediction of the profitability factor. In the publishing industry, $\beta_{\mathrm{RMW}}$ produced the opposite phenomenon: the factor was insignificant before the outbreak but significant and positively correlated after the outbreak, with a value of 0.61 . That may be because business in the publishing industry continues as normal, with little impact on operating cash flow. Moreover, before the epidemic, the publishing industry was more profitable by publishing paper books based on tradition. However, in the epidemic, the publishing industry was forced to try digital transformation. During the pandemic, people buy fewer printed books and newspapers instead of buying electronic books or periodicals online. Electronic transaction data from statistical networks may be a more efficient way of forecasting corporate profitability than actual print and retail records, which may be why RMW has become effective in publishing. The CMA factor remained significant and negatively correlated in the entertainment industry, from -0.45 to -2.02 , while remained insignificant in the publishing industry. The paper argues that the indicative value of CMA factors in these two industries is not large.

\section{CONCLUSION}

This paper used Fama-French five-factor model to perform multiple linear regression on entertainment and publishing industry data before and after the COVID-19 outbreak. The validity of the model in the above industries is tested and analyzed in combination with the actual situation of the industry.

The results indicate that the market risk factor and size factor is the best in the model. The rise of these two factors indicates that the industry concerned in this paper has received a small negative impact compared with the market, and this paper analyzes the reasons in 
many aspects. The study also found that the book-tomarket ratio only worked in a pandemic. That may be because of investor sentiment. However, the profitability and investment factors do not show the same changes in the two industries, and this article speculated on the reasons.

The research makes a statistical demonstration of the validity of the Fama French five-factor model in specific industries and studies the impact of the epidemic on specific industries. As for the impacts of COVID-19 on the industry that cannot be accurately described in the model, the author guesses the possibility of realistic phenomena corresponding to these impacts, providing ideas for subsequent research.

\section{REFERENCES}

[1] Lee, H. S. (2020). Exploring the Initial Impact of COVID-19 Sentiment on US Stock Market Using Big Data. Sustainability, 12(16), 6648. MDPI AG. Retrieved from http://dx.doi.org/10.3390/su12166648

[2] Phan, D. H. B., \& Narayan, P. K. (2020). Country Responses and the Reaction of the Stock Market to COVID-19-a Preliminary Exposition. Emerging Markets Finance and Trade, 56(10), 2138-2150.

[3] Tashanova, D., Sekerbay, A., Chen, D., Luo, Y., Zhao, S., \& Zhang, T. (2020). Investment Opportunities and Strategies in an Era of Coronavirus Pandemic. Social Science Research Network.

[4] He, P., Sun, Y., Zhang, Y., \& Li, T. (2020). COVID-19's Impact on Stock Prices Across Different Sectors-An Event Study Based on the Chinese Stock Market. Emerging Markets Finance and Trade, 56(10), 2198-2212.

[5] Nguyen, H. V., Tran, H. X., Van Huy, L., Nguyen, X. N., Do, M. T., \& Nguyen, N. (2020). Online Book Shopping in Vietnam: The Impact of the COVID-19 Pandemic Situation. Publishing Research Quarterly, 1-9. Advance online publication. https://doi.org/10.1007/s12109-02009732-2

[6] Cakici, Nusret, The Five-Factor Fama-French Model: International Evidence (October 14, 2015). Available at

SSRN: https://ssrn.com/abstract=2601662 http://dx.doi.org/10.2139/ssrn.2601662

[7] Hou, K. The Impact of Fama-French Five Factor Model on Retail Industry During the Outbreak of COVID-19.

[8] Nguyen, H. V., Tran, H. X., Van Huy, L., Nguyen, X. N., Do, M. T., \& Nguyen, N. (2020). Online
Book Shopping in Vietnam: The Impact of the COVID-19 Pandemic Situation. Publishing Research Quarterly, 1-9. Advance online publication. https://doi.org/10.1007/s12109-02009732-2

[9] Guren, C., McIlroy, T., \& Sieck, S. (2021). COVID-19 and Book Publishing: Impacts and Insights for 2021. Publishing Research Quarterly, $37(1), 1-14$.

[10] D. Li, J. Bai and Z. He, "Analysis of U.S. Game Industry Based on Fama-French Model under COVID-19," 2020 16th Dahe Fortune China Forum and Chinese High-educational Management Annual Academic Conference (DFHMC), 2020, pp. 112-116, doi: 10.1109/DFHMC52214.2020.00030. 